The submittec manuscript has been created by the University of Chicago as Operator of Argonne National Laboratory ("Argonne") under Contract No. W-31-109-ENG-38 with the U.S. Department of Energy. The U.S. Government retains for itself, and others acting on its behalf, a paid-up, nonexclusive. irrevocable worldwide license in said article to reproduce, prepare derivative works, dis. tribute copies to the public, and perform pub. licly and display publicly, by or on behalf of the Government.

\title{
Resonant Excitation of Plasma Wakefields using Multiple Electron Bunches
}

\author{
Manoel E. Conde and Wei Gai
}

Argonne National Laboratory, Argonne, Illinois 60439

\begin{abstract}
We plan to resonantly excite plasma wakefields using a train of electron bunches separated by an integer number of plasma wavelengths. The multiple electron bunches are generated by a photocathode based RF gun by splitting the laser beam into temporally separated pulses. The amplitude of the wakefields generated by the sequence of bunches is expected to be higher than that generated if all charge had been in only one bunch, because this single bunch would be considerably longer than the individual sub-bunches due to space charge effects in our gun.
\end{abstract}

\section{INTRODUCTION}

High charge short electron bunches are needed to achieve high accelerating gradients in electron beam driven plasma wakefield accelerators. Electron bunches generated by photocathode based RF guns in general become longer as the bunch charge is increased. An attractive alternative to generating high charge single electron bunches is to generate a train of bunches separated by a plasma wavelength (1). In this way the plasma wakefield is resonantly excited by the bunch train and each bunch can be kept short because the total charge is distributed over many bunches.

\section{GENERATION OF MULTIPLE BUNCHES}

We can generate multiple electron bunches from our photocathode based RF gun simply by splitting the laser beam into a sequence of temporally separated pulses. The delay between the pulses needs to be equal to the plasma wavelength, which in our case is about $6 \mathrm{~mm}$ (assuming a plasma density of $3 \times 10^{13} \mathrm{~cm}^{-3}$ ). This delay between the laser pulses will introduce an energy difference between the various electron bunches in the train, as they will be emitted from the photocathode at different phases of the RF power that is present in the gun. However, since our RF gun operates at 1.3

Submitted to the proceedings of the Advanced Accelerator Concepts Workshop, Baltimore, MD, July 6-11, 1998. 


\section{DISCLAIMER}

This report was prepared as an account of work sponsored by an agency of the United States Government. Neither the United States Government nor any agency thereof, nor any of their employees, make any warranty, express or implied, or assumes any legal liability or responsibility for the accuracy, completeness, or usefulness of any information, apparatus, product, or process disclosed, or represents that its use would not infringe privately owned rights. Reference herein to any specific commercial product, process, or service by trade name, trademark, manufacturer, or otherwise does not necessarily constitute or imply its endorsement, recommendation, or favoring by the United States Government or any agency thereof. The views and opinions of authors expressed herein do not necessarily state or reflect those of the United States Government or any agency thereof. 


\section{DISCLAIMER}

Portions of this document may be illegible in electronic image products. Images are produced from the best available original document. 


\section{THE AWA ELECTRON GUN PERFORMANCE}

It is obviously easier to generate shorter electron bunches when the bunch charge is smaller. As we increase the bunch charge, space charge forces become more intense, in general making the bunch longer. We have measured the dependence of bunch length on charge for the AWA drive gun (2). Figure 2 shows the result of this measurement. Bunch length was measured with an aerogel Cerenkov radiator and a streak camera (Hamamatsu M1952/C1587). Bunch charge was measured with an integrating current transformer (Bergoz ICT-082-070-20:1). The plot shows the FWHM of the bunch length and also the $95 \%$ RMS values (i.e. the RMS calculated using only the section of the pulse profile with intensity within $95 \%$ of the peak value, with the purpose of discarding the effect of the small background noise at the wings of the distribution). The ratio between the 95\% RMS and the FWHM values shows that the pulses are not gaussian. Each point on the graph corresponds to the average of three pulses. The large fluctuation in the FWHM of the pulses also shows that the detailed shape of the temporal profile varies considerably from pulse to pulse.

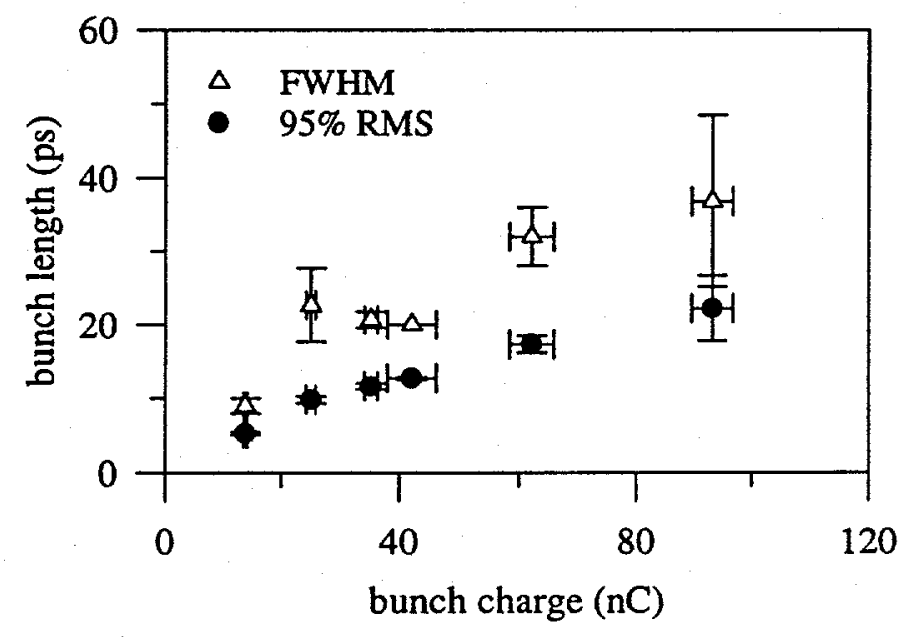

FIGURE 2. Measurements of electron bunch length as a function of bunch charge. The error bars indicate the standard deviation of the average of three pulses. 

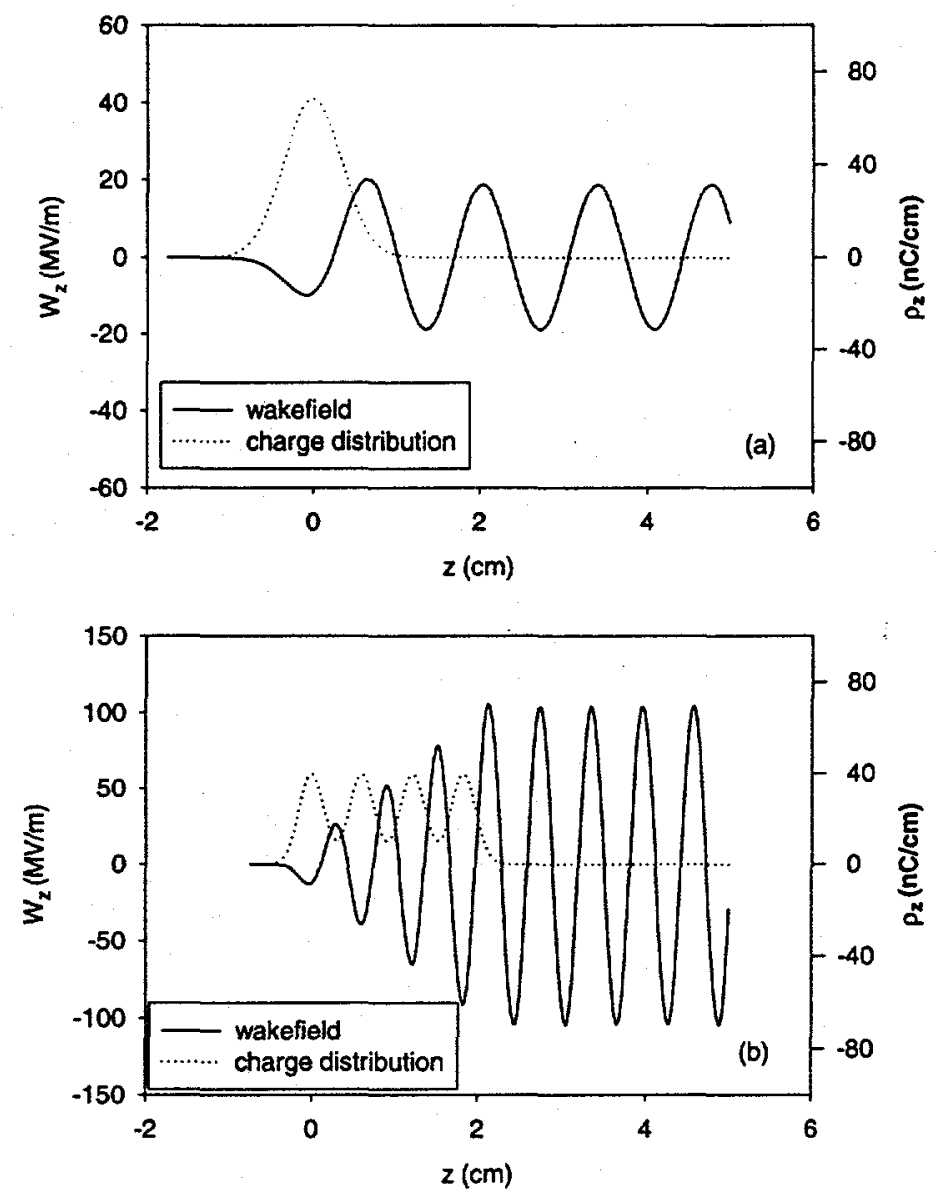

Figure 3. Wakefield amplitude and bunch charge distribution: (a) single $60 \mathrm{nC}$ drive bunch with $\sigma_{\mathrm{z}}=$ $3.5 \mathrm{~mm}$; plasma density is $6 \times 10^{12} \mathrm{~cm}^{-3}$; (b) train of four $15 \mathrm{nC}$ bunches with $\sigma_{z}=1.5 \mathrm{~mm}$; plasma density is $3 \times 10^{13} \mathrm{~cm}^{-3}$.

\section{REFERENCES}

1. Russian paper.

2. M.E. Conde, W. Gai, R. Konecny, X. Li, J. Power, P. Schoessow, and N. Barov, Phys. Rev. ST-AB 1, 041302 (1998). 